\title{
Propulsion System Modeling and Takeoff Distance Calculations for a Powered-Lift Aircraft with Circulation-Control Wing Aerodynamics
}

\author{
Mark Waters ${ }^{1}$, Cassy Anthony ${ }^{2}$, Gregory McKenzie ${ }^{3}$, and David D. Marshall ${ }^{4}$ \\ California Polytechnic State University, San Luis Obispo, CA, 93407-0352
}

\begin{abstract}
The computation of takeoff distance for powered-lift aircraft is complicated because of the coupling of aerodynamic performance (lift, drag and moment coefficients) with forward speed. Cal Poly has developed an analysis procedure to capture this coupling, and the development of this procedure is continuing. In the past year, Cal Poly has completed a Phase I NRA contract from the NASA for the configuration development and modeling of CESTOL aircraft. The primary objective of this contract was to identify an aircraft configuration in enough detail to proceed into a Phase II contract to design and construct a large scale wind tunnel model followed by a wind tunnel test to measure both aerodynamic performance and noise. Four aircraft configurations have been developed, and all but one of the configurations use circulation control wing aerodynamics (CCW) to produce powered-lift aerodynamic effect for the wing. The aircraft configuration selected for the Phase II contract makes extensive use of CCW to develop high lift aerodynamics for takeoff and initial climb and again for final descent and landing.
\end{abstract}

An additional goal for the Phase I project was the CFD modeling of the aerodynamics of a CESTOL aircraft, and to use the CFD results to develop a new aerodynamic meta-model. In addition, a meta-model for propulsion performance was to be developed and the two meta-models were to be integrated into an upgraded takeoff code written in MATLAB. These models all combined were to demonstrate an up-graded version of the Cal Poly takeoff performance procedure. However, at present, the aerodynamics meta-model is not yet complete and work will continue on into Phase II. Thus, no specific takeoff performance is demonstrated in this paper. However, in this paper details of the aircraft configurations are presented, the options available to proceed high pressure air to the wing slots to produce $\mathrm{CCW}$ aerodynamics are discussed, the propulsion metamodel is defined, the analysis procedure for the aerodynamics meta-model is discussed and the up-graded takeoff program is discussed.

${ }^{1}$ Lecturer, Aerospace Engineering Department, Member.

${ }^{2}$ Graduate Student, Student Member.

${ }^{3}$ Under-Graduate Student, Student Member.

${ }^{4}$ Associate Professor, Senior Member. 


\section{Nomenclature}

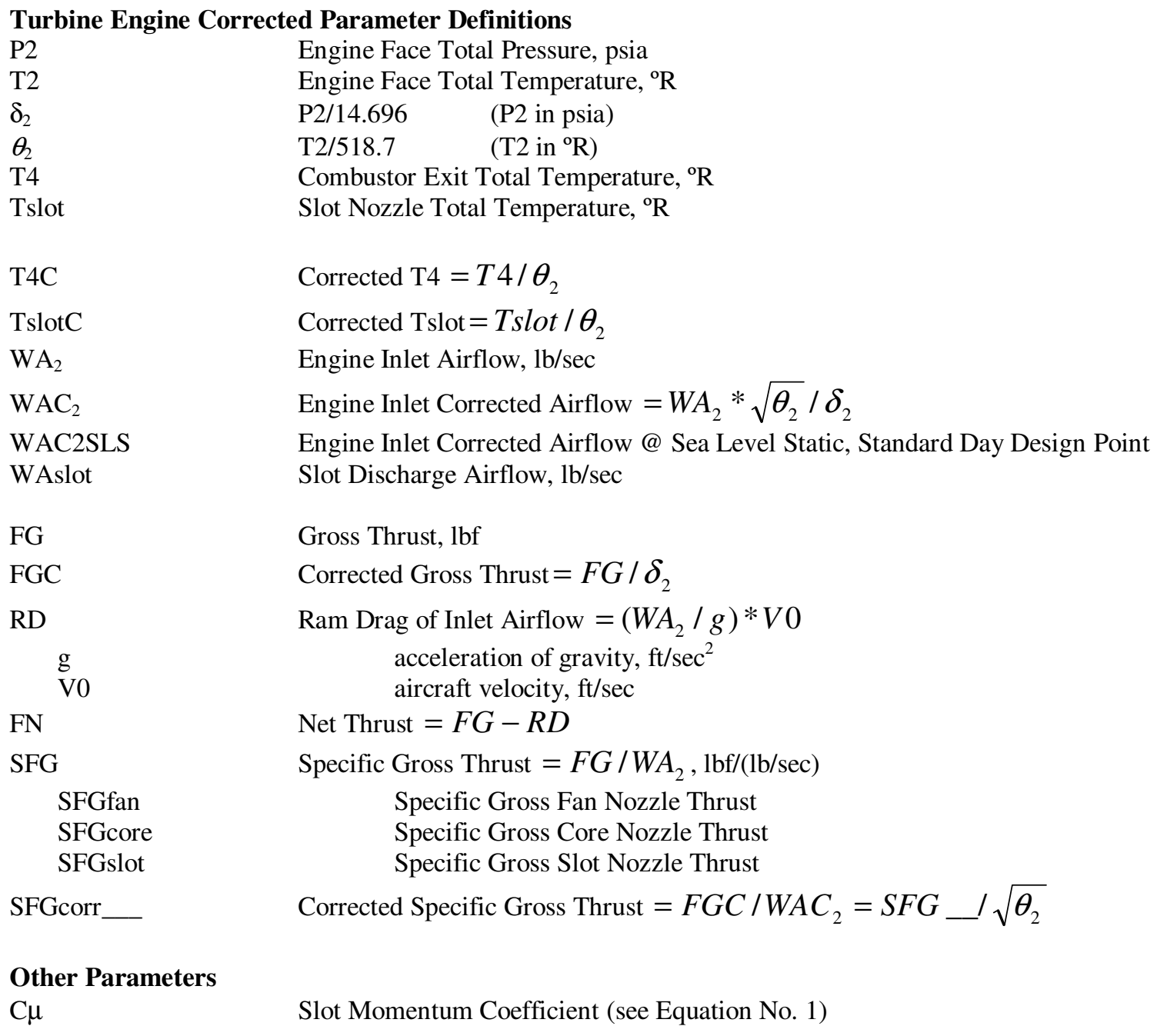




\section{Introduction}

Takeoff and initial climb performance calculations for a STOL aircraft using powered-lift are complicated by the fact that the propulsion system interacts with the aerodynamics of the wing. The maximum lift coefficient and thus the stall speed are constantly changing as the aircraft accelerates. Thus the FAA Part 25 definitions for minimum control speed (ground and in-flight), decision speed (for balanced field length calculation) and the minimum speed required to maintain climb gradients become meaningless because they are all keyed to a fixed stall speed. To address this problem a methodology has been developed at Cal Poly for powered-lift aircraft using circulation control wing $(\mathrm{CCW})$ aerodynamics (Ball, Turner, Marshall ${ }^{1}$ ). The methodology requires the development of a meta-model to produce the changing aerodynamic forces and moments that result during ground roll acceleration and initial climb.

Thrust also changes with ground speed, and a relatively simple model was used in the referenced paper to account for changing net thrust during ground roll and initial flight. In subsequent work, a more detailed propulsion model has been developed using the Cal Poly Turbine Engine program (CPTE). Data from this model are generalized using the traditional dimensional analysis parameters used with propulsion systems to produce corrected airflow ratio (corrected airflow/design point corrected airflow), corrected specific thrust and corrected specific fuel consumption over a range of engine power settings. This propulsion metamodel is robust in that airport altitude and ambient temperature are inputs to the model. For example, highhot takeoff performance can be computed. The two meta-models, aerodynamics and propulsion, will be coupled and will be used in a newly developed takeoff program to compute a time history of the takeoff distance from aircraft brake release up to the required screen height and then the point where the flaps are completely retracted.

During the past year, Cal Poly has been working on a NASA NRA contract ${ }^{2}$ to develop aircraft design options for an CESTOL (Commercial Extreme Short Takeoff and Landing) aircraft. Four different aircraft were designed in Phase I, which is now complete, and Phase II of the contract is now underway. For this phase of the contract, one CESTOL aircraft design from Phase I has been selected, and the goal is to design and construct a large scale model of this aircraft design, and then to test for aerodynamic performance and noise in a large scale wind-tunnel. The test will be conducted in the Air Force National Full Scale Aerodynamic Complex (NFAC), a large scale wind tunnel at Moffett Field, CA. This test is planned to take place in early 2010 .

The original plan for this paper was to complete an aerodynamics meta-model for the CESTOL aircraft design selected for the Phase II test. This model would then be coupled with the new and more detailed propulsion meta-model to compute powered-lift takeoff data just as was done in reference 1 . However, the complete CFD aerodynamic modeling of this aircraft design including the full CCW powered-lift effects has proven to be a difficult task. This work will be completed during the NRA Phase II contract period, and the original plan to compute powered-lift takeoff performance will then be completed and reported.

This paper will serve as an interim step in which the powered-lift aircraft design will be described in some detail. Included is a discussion of the different options that are available to provide high pressure air or gas to slots to the wing for $\mathrm{CCW}$ aerodynamic performance. Two different turbofan engine cycles are evaluated, and the modeling of the propulsion system, including both engine and wing slots, is demonstrated. In addition, a meta-model for the propulsion system is presented. A discussion of the details of the aerodynamic meta-model, yet to completed, is presented, and the takeoff performance model that will be used to apply the aerodynamic and propulsion meta-models is described.

\section{Powered-Lift Aircraft Definition}

The project goal for the Cal Poly NRA contract was to develop a set of powered-lift CESTOL aircraft configurations all designed for a payload of 100 passengers. As described above, one configuration has been selected for the development of a wind tunnel model and test. During Phase I, each aircraft 
configuration was developed in sufficient detail to meet FAA requirements for cabin, cargo bay and landing gear design. Also, weight estimates were done in sufficient detail to balance the aircraft and design the empennage. With CESTOL field length requirements in mind, all aircraft were designed with a sealevel static total thrust to gross weight ratio of 0.45 , although it should be emphasized that this ratio may vary once the aircraft aerodynamics are complete and the propulsion system sized precisely for the required takeoff distance. Solid models of the four configurations completed in the Phase I study are shown in Figure 1.

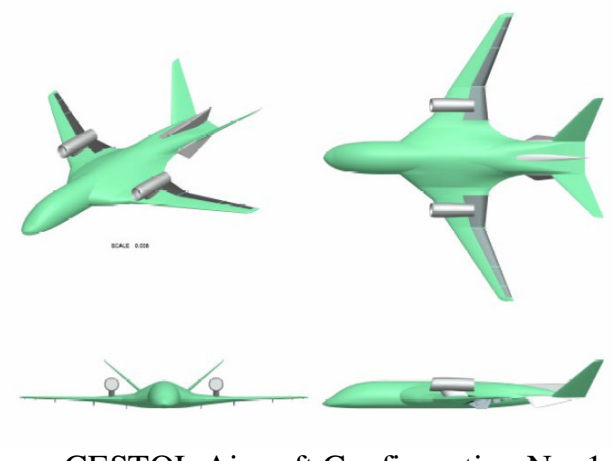

CESTOL Aircraft Configuration No. 1
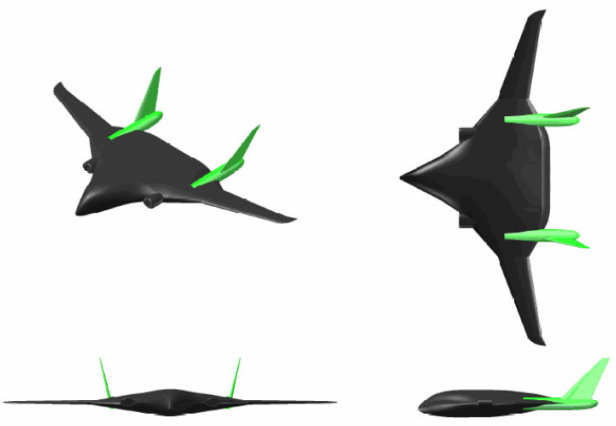

CESTOL Aircraft Configuration No. 3
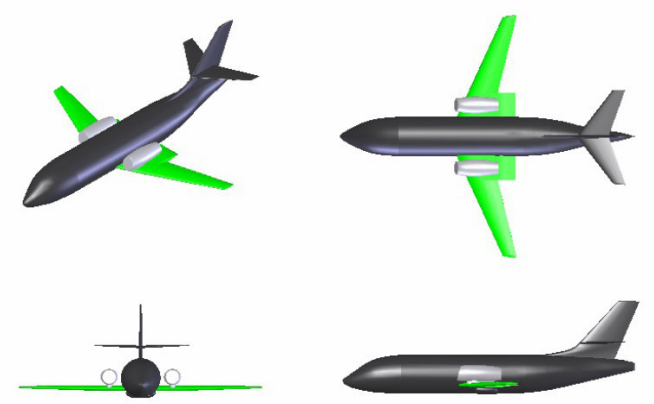

CESTOL Aircraft Configuration No. 2
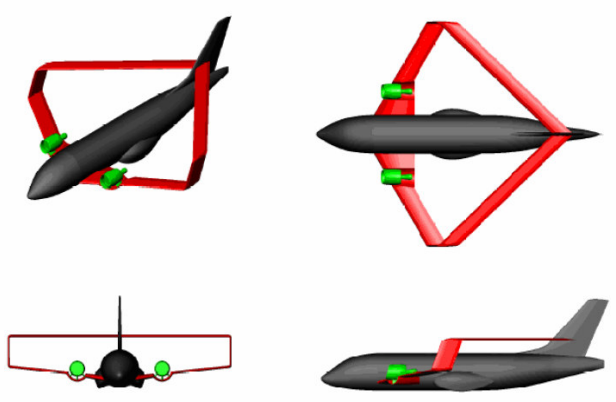

CESTOL Aircraft Configuration No. 4

Fig. 1. CESTOL Aircraft Configurations Developed in the Cal Poly NRA Contract

Aircraft configuration No. 1 is termed a "Hybrid Blended-Wing-Body, HBWB" with the wing in-board panels blending into the fuselage and the wing out-board panels more of a traditional high aspect ratio wing. Circulation-Control-Wing (CCW) aerodynamics are achieved with engine fan flow supplying high pressure air to wing leading edge and trailing edge slots. Aircraft configuration No. 2 is a conventional wing-body aircraft with over-the-wing (OTW) blowing achieved with engine exhaust flow over the extended in-board wing flap system. Aircraft configuration No. 3 is the classic blended-wing-body (BWB) design similar to that now being developed by the Boeing company. This aircraft proved to be very difficult to balance in the small size required for the study, but balance was achieved. Aircraft Configuration No. 4 used the fuselage of Configuration No. 2 and integrated a joined-wing design to it. The aircraft configuration selected for the Phase II study was Configuration No. 1, and it is used as the aircraft configuration design for this paper.

The 3-view of the Hybrid BWB aircraft is shown in Figure 2. Note the turbofan engines located above the wing supported on short pylons. The intent in having engines above the wing is to reduce noise during takeoff and landing, and an important tradeoff to be conducted in the Phase II wind tunnel test will be to vary the chord-wise location of the engines considering both performance and noise. 


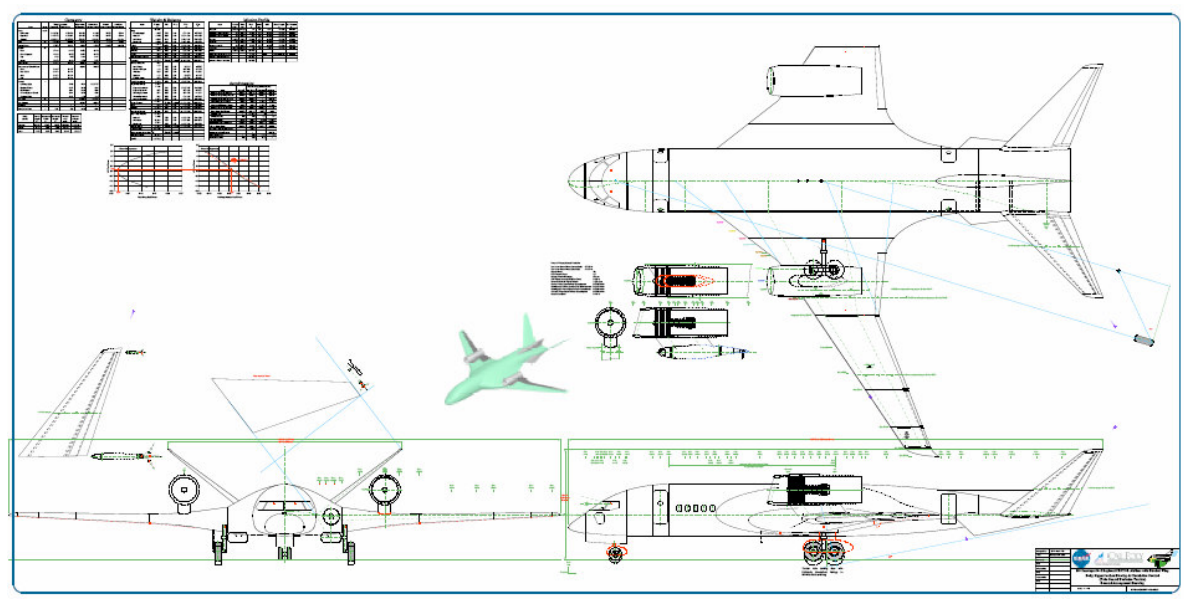

Fig. 2. General Arrangement of the Hybrid BWB CESTOL Aircraft

A second 3-view demonstrating the in-board profile of the aircraft is shown in Figure 3. Details of the cabin seating, galleys and lavatories are shown. This arrangement conforms to standard FAA requirements and practice. Also note the fan air bleed to the slots in the wing leading and trailing edges.

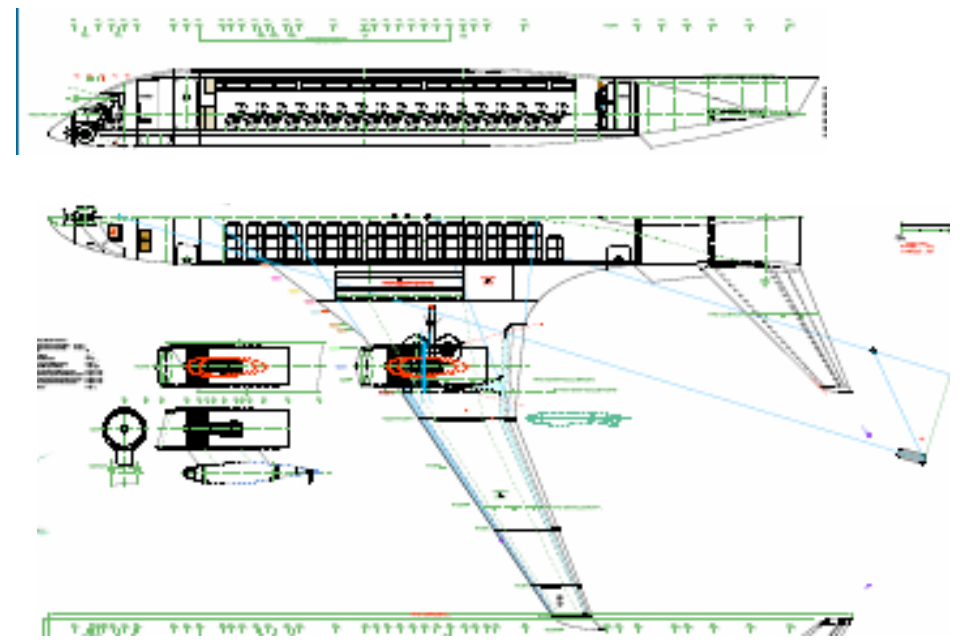

Fig. 3. Inboard Profile Views for the Hybrid BWB CESTOL Aircraft

\section{Propulsion System Definition}

The HBWB aircraft design uses two high bypass ratio turbofan engines as the primary source of propulsion. Two different engine cycles were evaluated, and they are defined in this section. The wing trailing edge wing slot with a high pressure source of air is the energy source for $\mathrm{CCW}$ aerodynamics to provide super-circulation of the flow over the wing and thus increased lift. High pressure air is ducted to a slot nozzle in the wing trailing edge to blow over a circular flap. The span of this slot extends over a major portion of the complete wing span, and the momentum of this slot jet produces thrust in the axial direction. In addition, there is a second slot with high pressure air blowing over an equally long span at the leading 
edge of the wing. High pressure from this slot is necessary to preclude flow separation near the wing leading edge. In this study, it is assumed there is no axial thrust from the leading edge slot flow.

A major design consideration is the source of this high pressure air, and this subject is also discussed in this section. Slot blowing is operable only during takeoff and initial climb and again in final approach and landing. Thus, there is no source air to the slots during a major portion of the aircraft mission - climb after the wing flaps are retracted, cruise and descent before the wing flaps are deployed.

\section{A. Turbofan Engine Cycles}

Two engine cycles were considered in the project. Both assume improved technology in terms of increased combustor exit temperature with essentially no increase in the required cooling air to the turbines. This is a major technology issue consistent with the NASA N+2 technology timeframe (the year 2025 as the operational introduction data). The engines are separate flow turbofan engines (separate fan and core nozzles), and the distinction between the two engines is the values for design point fan pressure ratio and bypass ratio. Both engine cycles have identical overall pressure ratio and high pressure compressor pressure ratio. These two engines are designated as "advanced conventional turbofan cycle, ACTF" and "advanced geared turbofan cycle, AGTF." The designation as a geared turbofan for the AGTF is a direct result of the gearbox in the fan hub. At nominally a bypass ratio of eight (8) the tradeoff to provide a gearbox in the fan hub to decouple the fan shaft speed and the low pressure turbine shaft speed favors having a gearbox. This is consistent with the current geared turbofan (GTF) engine now under development by Pratt and Whitney Aircraft.

Bypass Ratio

Fan Pressure Ratio

Low Pressure Comp. Pressure Ratio

High Pressure Comp. Pressure Ratio

Overall Pressure Ratio

Combustor Exit Temperature. ${ }^{\circ} \mathrm{R}$

$\begin{array}{rr}\text { ACTF } & \text { AGTF } \\ 5 & 10 \\ 1.7 & 1.5 \\ 2.118 & 2.4 \\ 8.400 & 8.400 \\ 30.24 & 30.24 \\ 3360 & 3360\end{array}$

An important factor, with respect to the flow at the wing slots and powered-lift performance, is the fan pressure ratio. An obvious question to ask is why not design an engine with higher fan pressure ratio, slightly greater than 2.0, in order to achieve higher momentum coefficients when bleeding air to the wing slots. But, a fan pressure ratio this high will require a two-stage fan, and it will result in a lower bypass ratio, less than five. The potential increase in specific fuel consumption (TSFC) at cruise and overall mission fuel burn is an overriding consideration in keeping the fan pressure ratio low and the bypass ratio high. .

It is to be expected that engines for a very short takeoff aircraft, like a CESTOL aircraft, would be sized by the takeoff requirement. But, as a result of the low lapse rate of the AGTF engine, it is possible that this engine would be sized at the top-of-climb. Lapse rate is defined at the engine thrust at the top-of-climb divided by the rated thrust at the sea level static design point, and this parameter is reduced as the engine bypass ratio is increased. Nonetheless, cruise TSFC is an important performance factor and the choice of engine cycle can only be determined once the full aircraft design is modeled and the mission performance is simulated to determine total fuel burn.

The total aircraft thrust while a fraction of the fan flow is being ducted to the wing slots will include the axial thrust from the wing slots as well as thrust from the engine core nozzle and thrust from the fan nozzle. Flow rates to the fan nozzle will change significantly with or without bleed flow to the wing slots. Thus, a variable area fan nozzle design will be required to balance continuity when a portion of the fan flow is being ducted to the wing slots. Figure 4 is a simple free-body diagram for the wing. The free-body boundary follows the contour of the wing and crosses normally at the slot nozzles. In the results shown

American Institute of Aeronautics and Astronautics 
later in this paper, the axial component of thrust from the leading edge slot is not included in the performance values. How to include the leading edge momentum force is to be resolved with the development of the aerodynamics meta-model, yet to be developed.

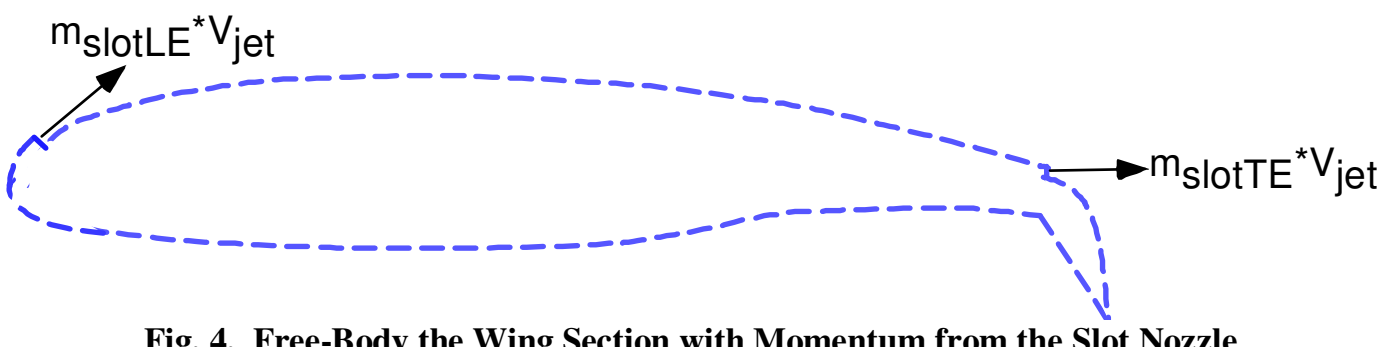

Fig. 4. Free-Body the Wing Section with Momentum from the Slot Nozzle

The CFD aerodynamic analysis accounts for all viscous and pressure forces on the wing, including the super-circulation of flow due to the turning of the slot flow over the trailing edge flap. However, this analysis does not include the momentum crossing the free-body boundary at the wing slot nozzle exit. This momentum is the gross thrust from the wing trailing edge slot, and it is added to the gross thrust of the core and fan nozzles to compute total gross thrust per wing. The ram drag of the airflow into the engines is computed and subtracted from gross thrust to obtain net thrust.

\section{Momentum Coefficient, Slot Geometry \& Sources for Slot Airflow}

A measure of the flow at the wing slots is the momentum coefficient, $C \mu$, which is defined as the momentum of the jet sheet discharging from the slot divided by the product of free stream dynamic pressure, $q 0$, and the wing reference plan-form area, Sref. The momentum is the product of the slot mass flow, $\dot{m}_{S L O T}=\dot{W}_{S L O T} / g$, and the slot discharge velocity, $V_{S L O T}$.

$$
C \mu=\frac{\dot{m}_{S L O T} * V_{S L O T}}{q 0 * \text { Sref }}
$$

The lift coefficient of the wing increases with increasing $\mathrm{C} \mu$, and one way to do this is to increase the slot velocity to sonic flow. Even higher velocities are possible with the slot designed with higher critical pressure thus requiring a convergent-divergent slot nozzle. So, with this in mind, the pressure at the slot should create sonic or near sonic flow. This will be achieved with a pressure approximately 1.9 times ambient pressure (i.e., the slot nozzle pressure ratio will be critical - nominally 1.9).

Although lift coefficient increases with higher values of $C \mu$,. the angle of attack at which stall will occur is reduced with increased $\mathrm{C} \mu$, and it has been determined that slot blowing from the wing leading edge is also required to preclude flow separation at the wing leading edge. Typical flow rates to the wing leading edge slot are $60 \%$ of the flow rate to the trailing edge slot.

\section{A. Slot Geometry}

An important feature of CCW aerodynamics is the geometry of the slot. Theoretically, the slot can be the full span of the wing, but there will be obvious design constraints. For the HBWB aircraft configuration the slot begins just outboard of the turbofan engines, and the slot span to wing span ratio is 0.709 . The other two wing trailing edge geometric design parameters are the flap radius and the slot height. The data shown in Figure 5 are taken from the reference noted on the figure. On the figure, shown in green, is a region which has been determined to be most effective in promoting coanda flow over the trailing edge flap. The two ratios shown on the abscissa and ordinate of the figure are the slot height to wing chord ratio and the slot height to flap radius ratio, respectively. A second region shown on the figure in blue is the design space that has been considered for this NRA project. As can be seen, the slot-chord ratio is allowed to increase up to a value of 0.0042 , which exceeds the effective range (green) boundary as shown. 
Robert Englar ${ }^{*}$, a co-author of these data, estimates that the loss in performance with this size slot would not degrade $\mathrm{CCW}$ aerodynamic performance significantly. As will be shown, maximizing this ratio is important to the momentum coefficient of the slot flow. For the design space of the project, the slot height - flap radius ratio does not exceed the effective region boundary, which is 0.05 .

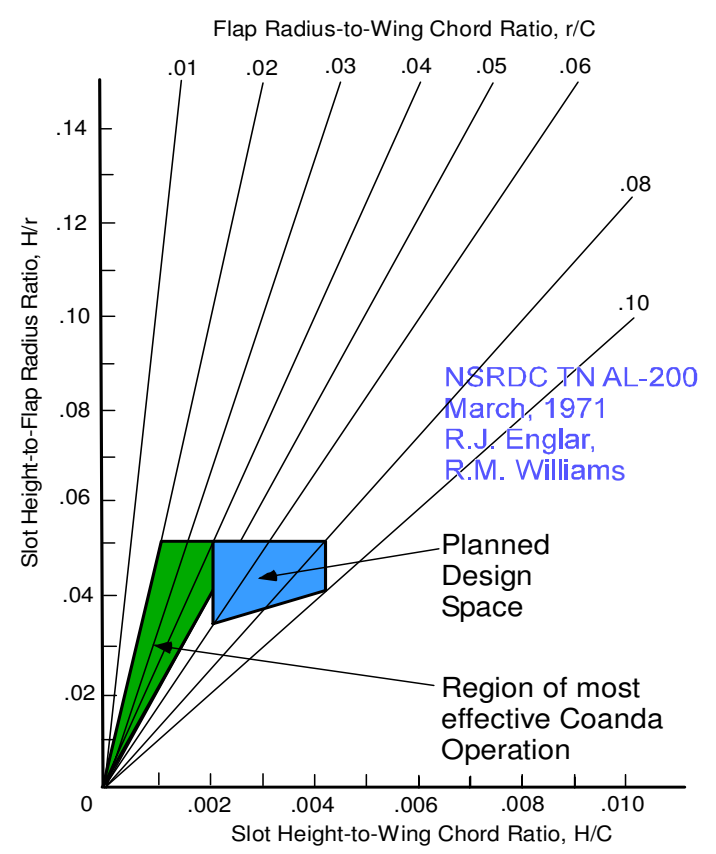

Fig. 5. Trailing Edge Slot and Flap Geometry

* Mr. Robert Englar is currently working at the Georgia Tech Research Institute (GTRI). GTRI is a sub-contractor to the Cal Poly CESTOL project, and Mr. Englar is an active participate.

\section{B. Source Air for Slots, Option No. 1}

Four different sources of high pressure air have been considered: 1) bleed air from the engine fan duct, 2) bleed air from the engine core, 3) bleed air from the exhaust duct of a mixed flow turbofan engine, 4) integration of separate fan gas generators, one in each wing root, to provide high pressure fan air. Each option has undesirable features that are discussed in the following sub-sections.

For the first option for high pressure air supply, bleed air is taken from the fan duct of a separate flow turbofan engine. Immediately one can anticipate the penalty associated with this option because the fan pressure of the two engines being considered are 1.5 and 1.7 for the AGTF and ACTF engines, respectively. As discussed above, it is desirable to have sonic flow at the slot, and this will require a fan pressure ratio of 2.0 or even slightly greater accounting for supply duct pressure losses. Nonetheless, this option for slot air is relatively straight forward requiring a blocking device in the fan nozzle with a scroll to collect bleed air to be ducted to the wing slots. Also required is a variable area fan exhaust unless all of the fan air is ducted to the wing slots.

\section{Source Air for Slots, Option No. 2}

The second option for the high pressure air supply to the wing slots is to bleed air from the engine core. This option for source air to the slots is appealing in the sense that the bleed point pressure can be selected to give sonic flow at the wing slot. However, this option definitely will not work for the high quantity of slot air flow required for the HBWB aircraft design. As will be shown in the Results section, the required bleed flow exceeds the core flow, e.g., for a bypass ratio of 5 , the core flow is $20 \%$ of the fan flow. As will 
be shown, bleed flow fractions from the fan to the slots are $38-58 \%$ of the fan flow for the AGTF and ACTF engine cycles, respectively. In fact, bleed flows of any amount from the core of the engine will be very detrimental to engine performance because the energy into the cycle is obtained by combusting the core flow and expanding this flow through the high and low pressure turbines. Bleed air from the core will be a major penalty to the cycle, and it is not considered as a viable option for high pressure air to the wing slots.

\section{Source Air for Slots, Option No. .3}

The third option for high pressure air supply to the wing slots is to have a mixed flow turbofan engine and to bleed exhaust gas from the engine tail pipe ahead of the exhaust nozzle. This option has the problem of bleeding hotter exhaust gas rather than relatively cool fan air. An alternative is to bleed from the fan duct ahead of the mixing plane. However this is not desirable, and it may not be at all feasible. Static pressure must balance for the fan and the core in the mixing region, and it is not clear that this balance could be achieved with and without a large amount of bleed flow ahead of the mixing plane. Thus, for this option bleed air must be taken from the exhaust duct to provide high pressure gas to the wing slots. Although the hotter gas will increase slot exhaust velocity, it was determined for the two engine cycles studied that the nozzle pressure was nominally the same as the fan discharge pressure. Thus, for a given bleed flow, any potential increase in the momentum coefficient would be minimal.

\section{E. Source Air for Slots, Option No. 4}

The fourth option for the high pressure air supply is a completely different concept. Instead of bleed air or gas from the main turbofan engines, air is supplied from the fan duct of a fan gas generator. Two such gas generators would be installed, one per wing, and they would be designed with a fan pressure ratio of nominally 2.1 to provide sonic flow at the wing slots accounting for losses in the supply ducts to the slots. For this type of machine, the combustor exit temperature would be nominally $2360{ }^{\circ} \mathrm{R}$, which is low enough not to require any turbine cooling air. The compressor pressure ratio would be low, nominally 4 , because low specific fuel consumption is not a paramount issue. Also, the nozzle pressure ratio is designed to be approximately 1.03, just enough to maintain flow through an exhaust nozzle. The bypass ratio of the fan gas generator is a fall-out from the analysis, and it is nominally 3.5. Such a machine could potentially serve as an auxiliary power unit (APU) for the aircraft.

Having additional rotating machinery in the aircraft is not desirable, but these machines would be extremely simple with a two stage fan and a single centrifugal compressor. A single spool design versus a twin spool design is possible. A major issue is the frontal area of the fan gas generator. The thick wing root section of the Hybrid BWB lends itself nicely to a reasonable installation of a fan gas generator. Such an installation is given in the sketches shown in Figure 6.
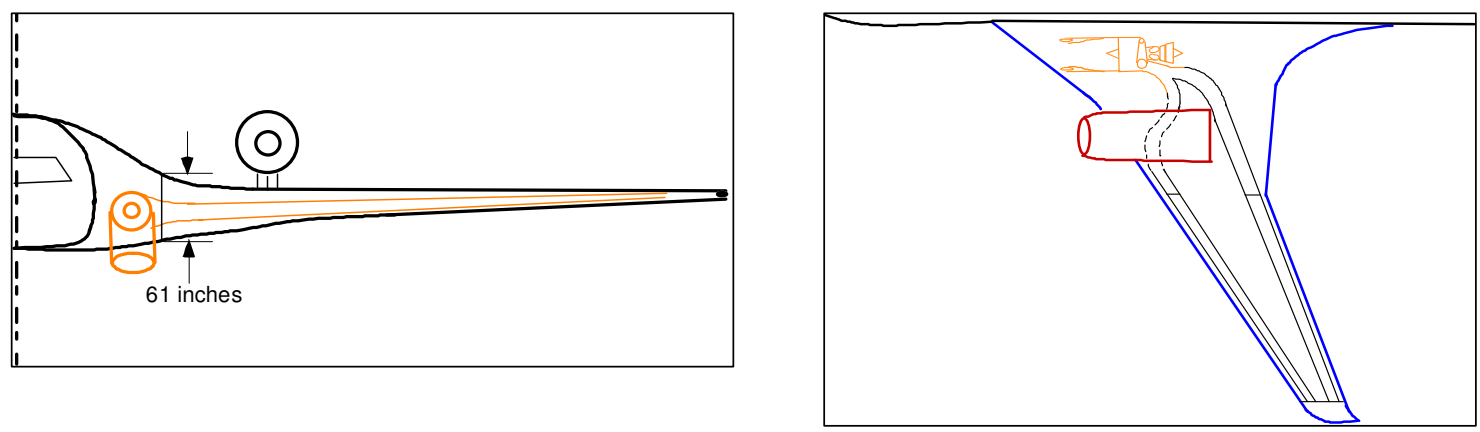

Fig. 6. Sketches of a Dedicated Fan Gas Generator Installed in a Hybrid BWB Aircraft

The advantage of this option for slot source air is that the fan gas generator can be designed to provide sonic flow at the wing slots and thus maximize the momentum coefficient and thus maximize additional 
lift. In addition, there is a safety issue. With a dedicated gas generator, the air source to the wing slots has been de-coupled from the main engines. With the air source from the engines, a loss of an engine will result in a loss in lift with the attendant problem of roll balance as well as yaw balance. This problem is eliminated with the use of dedicated gas generators. However, the added weight of the gas generators is obviously undesirable. Also, it is awkward to devise an inlet design. The sketch in Figure 6 suggests a drop-down scheme that would be deployed only when the CCW system was in operation. Such an inlet has been designed in some detail. It would work, stowing into the forward portion of the wing, but this location interrupts the wing spar requiring a box-like structure that adds weight. A straight-in inlet design through the wing leading edge, much like inlets for the British Vulcan and Victor aircraft, is also possible, but a means for closing this inlet once the gas generators cease to operate would be difficult.

\section{Wing Slot and Engine Sizing}

Of the four options for slot source air given in the previous section, option 1 with slot source air from the turbofan engine fan duct is considered best not only to develop a reasonable momentum coefficient, but for relative mechanical simplicity. Results showing trade-offs in momentum coefficient and engine size are given in this section.

The metric used to measure the effectiveness of the slot flow is the momentum coefficient, $C \mu$, at a Mach number of 0.09 (60 knots forward speed at sea level). This is approximately the liftoff speed for a CESTOL aircraft. The goal for $\mathrm{C} \mu$ at this Mach number is 0.40 , and to compute velocity at the wing slot a $5 \%$ loss of pressure from the fan discharge to the wing slot and a slot velocity coefficient of 0.985 is assumed.

Engine size is dictated by one of two factors - takeoff distance or rate of climb at the top of climb. With the aerodynamics analysis incomplete, it is not possible to compute takeoff distance with any precision, so to establish a size for the engines a takeoff sea-level-static thrust to aircraft weight ratio ( $\mathrm{TqW})$ of 0.45 is used as a baseline value. This is significantly larger than that for a typical transport aircraft, but it is presumed that the short takeoff distance requirement for a CESTOL aircraft will require a high $\mathrm{TqW}$. The other potential sizing point is the thrust to maintain a rate-of-climb (ROC) at the top of climb for some specified value. Typically $500 \mathrm{ft} / \mathrm{min}$ is required.

A remaining basic assumption is the gross takeoff weight of the aircraft. Using a basic weight fraction method, the gross weight of the 100 passenger HBWB CESTOL aircraft is computed to be nominally $95,000 \mathrm{lb}$, and this value is held constant for results shown in this paper. Obviously aircraft gross weight will vary somewhat with the change of engine cycle and engine size, but without detailed aerodynamic data it is not possible to completely model the aircraft. Thus, the data shown below will serve to establish trends, not precise results.

The requirement for top-of-climb is important to evaluate primarily because the two engine cycles vary in bypass ratio and fan pressure ratio, and the lapse rate of the higher bypass engine will be lower and may size the engine. Again, knowing the aircraft aerodynamics and the lift-drag ratio at the top-of-climb is needed.

\section{A. Wing Slot Sizing}

In Figure 7 with a TqW of 0.45, the momentum coefficient at the liftoff point (sea level, Mach $=0.09$ ) is shown over a range of ratios of slot flow to fan flow (slot flow ratio). Again, this slot flow ratio includes flow to both the wing leading edge and trailing edge slots. Data are shown for both engine cycles, and for a given slot flow ratio, the higher bypass ratio produces a higher momentum coefficient. This is in spite of the fact that the lower bypass engine has the higher fan pressure ratio and thus the higher slot nozzle pressure ratio and resulting exit velocity. However, for the same slot flow ratio, the quantity of airflow at the slot is greater for the high bypass ratio engine because of the higher fan flow. To meet the goal of having a $\mathrm{C} \mu$ of 0.4 , the slot flow ratios will be different for the two engine cycles, 0.56 and 0.67 for the high bypass ratio engine and the low bypass ratio engine, respectively. 
The data in Figure 8 show the other factor in slot flow design, namely the ratio of slot height to mean chord ratio (slot height ratio). For the slot flow ratios of the two engines, the slot height ratio is 0.007 for the high bypass ratio and 0.0047 for the low bypass ratio engine. Referring to Figure 5, the maximum value for the slot height ratio in what is called the "design space" is 0.0042 . For the high bypass ratio engine, if this value is used as a constraint not to be exceeded, the value of $\mathrm{C} \mu$ that can be achieved is 0.27 (curves in Figure 7 and 8 slightly extrapolated). For the low bypass engine a $\mathrm{C} \mu$ value of 0.365 can be achieved keeping the slot height ratio at 0.0042 .

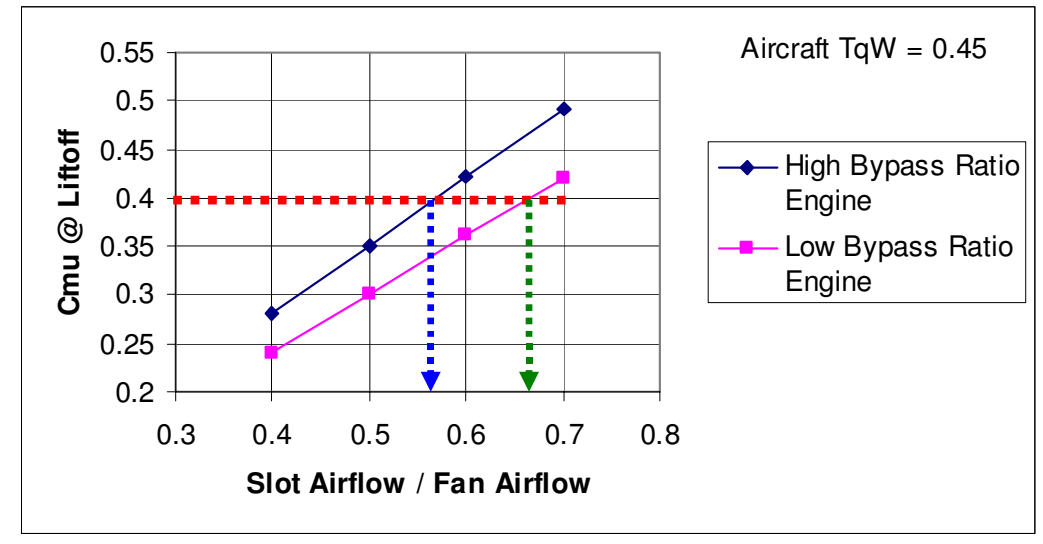

Fig. 7. Effect of the Slot Flow Ratio on the Momentum Coefficient at Liftoff

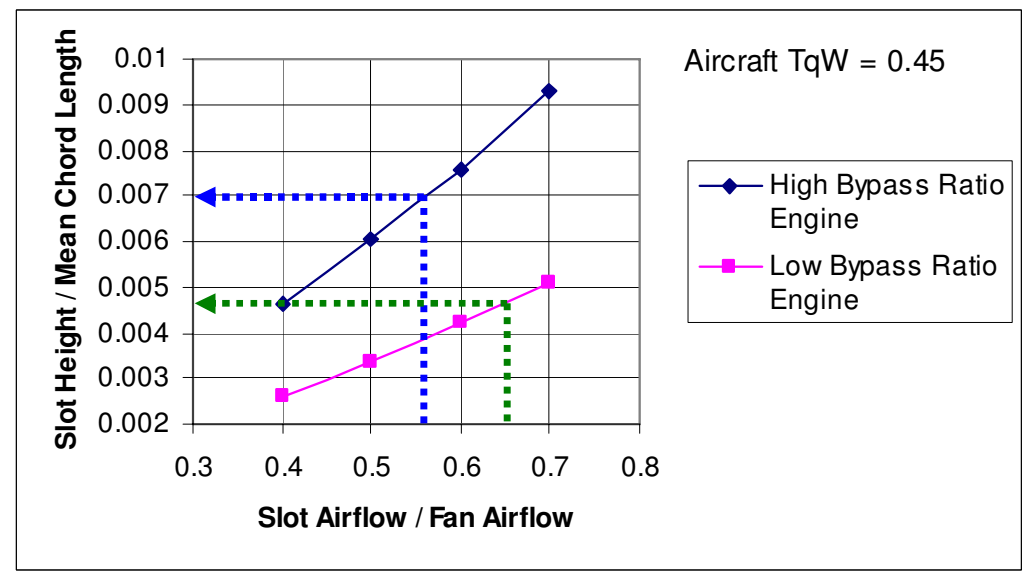

Fig. 8. Slot Flow Ratio on the Slot Height Ratio

The size of the engine measured by the fan tip diameter is also affected by the slot flow ratio. This is primarily because axial thrust from the slots is from the trailing edge slot only. With increasing slot flow ratio, more fan discharge flow is being ducted to the leading edge slot that produces no thrust. Another less important factor is that there are pressure losses assumed in the collection scroll and duct to the wing slots. The overall effect is shown in Figure 9, which also demonstrates the difference in engine diameter for the two engine cycles. For the two designs that meet the slot height ratio requirement of 0.0042 , the diameter of the high bypass ratio engine is 6.18 feet and that for the low bypass ratio engine is 5.32 feet. 


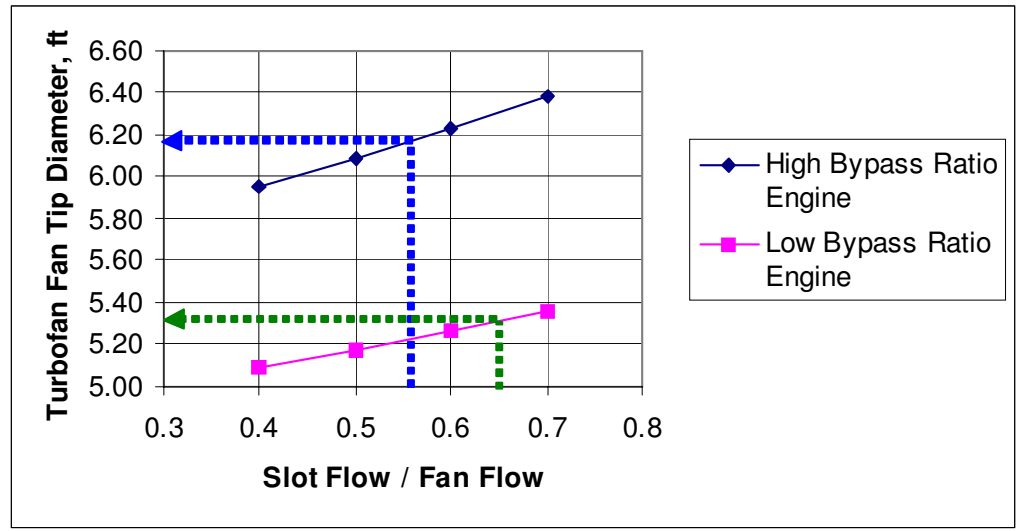

Fig. 9. Effect of Slot Flow Ratio and Engine Cycle on Engine Diameter

It is apparent that the goal of having $C \mu$ value of 0.4 at the liftoff point cannot be achieved with bleed flow from either of the two turbofan engine cycles chosen for this study. An engine with a fan pressure ratio slightly greater than 1.7 with a bypass ratio less than 5 would be required. Although considered mechanically complex and a penalty in terms of added engine weight, the dedicated fan gas generators given above as option number 4 for source air to the slots can meet the $C \mu$ requirement with ease as demonstrated in Figure 10.

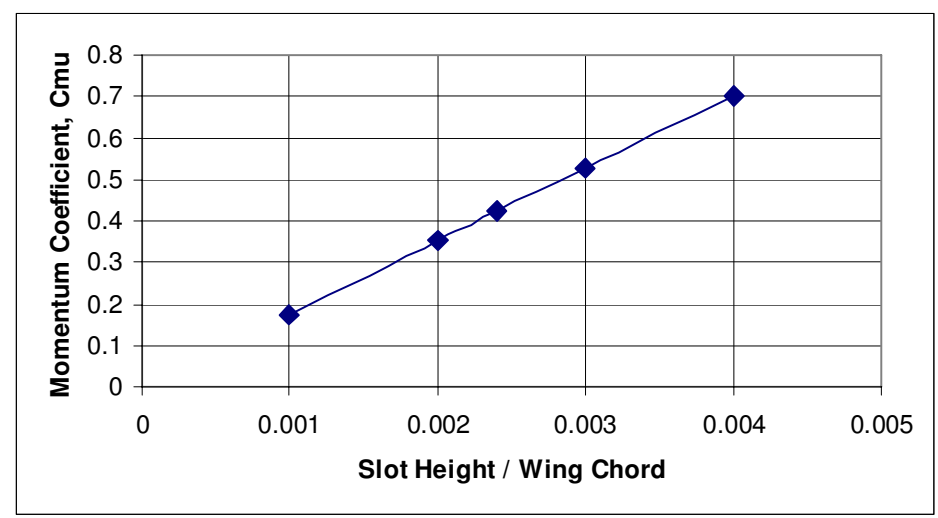

Fig. 10. Momentum Coefficient with Slot Height Ratio for Dedicated Fan Gas Generators

To meet the requirement, the slot height ratio can be as low a 0.0023 , which puts it in the "effective operation region" shown in Figure 5. Extending the slot height ratio up to the limit of the "planned design space" (again see Figure 5), which is a slot height ratio of 0.0042 increases the available $\mathrm{C} \mu$ up to approximately 0.72 .

The question remains whether the fan gas generators can fit into the wing root of the HBWB aircraft concept. The variation in fan tip diameter of the fan gas generator is shown in Figure 11, and it increases with the slot height ratio because of the increased requirement for fan air as the slot height increases. A wing thickness dimension of 61 inches in shown on Figure 6, and, realistically, a fan gas generator with a fan tip diameter of 45 inches would fit into the wing root space as shown in the figure. For this diameter, the slot height to wing chord ratio is 0.0032 , well within the design space defined in Figure 5. 


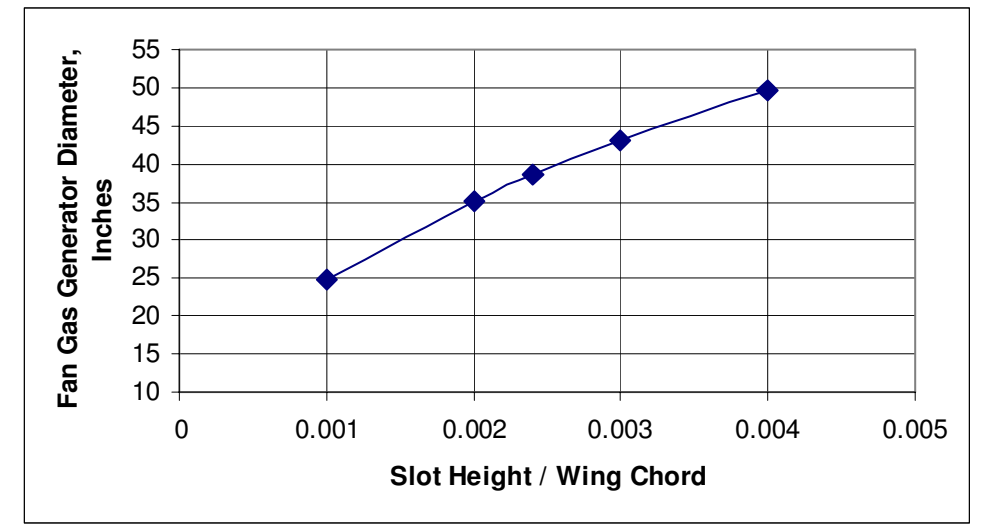

Fig. 11. Fan Gas Generator Frontal Diameter with Slot Height Ratio

\section{Discussion of the Planned Aero Meta-Model}

As described in the Introduction, the calculation of takeoff and balanced-field-length distance is complicated for an aircraft with CCW aerodynamics because of the interaction of the wing slot momentum coefficient, which is generated by the propulsion system, and the wing aerodynamics. A process to compute takeoff distance has been developed at Cal Poly, and it has been documented in Reference 1. This process involves meta-models for both aerodynamics and propulsion.

A meta-model is defined as a model of a model, and for CCW aerodynamic performance a fourdimensional design space was developed in the original study ${ }^{1}$ using the CFD program FLUENT to fully capture aerodynamic performance measured by lift, drag and moment coefficients. The independent parameters included Mach number (low speed up to 0.2), mass flow from the wing slots, trailing edge flap angle and angle of attack (for that portion of the takeoff after liftoff. A total of 40 CFD runs were performed at random points to produce the design space.

In the current Phase I NRA study, the intent was to repeat the takeoff distance study with one of the new configurations defined in the study. To do so requires the full CFD aerodynamic analysis of the complete aircraft including wings, fuselage, empennage and nacelles. In contrast, the first study modeled the wing to represent the complete aircraft.

The CFD modeling of the complete aircraft has proven to be a major step, and it is not yet complete. However, aerodynamic results using CFD analyses with FLUENT are very promising. Pressure coefficient contours for the HBWB aircraft at cruise (no slot flows) are shown in Figure 12. Similar data with slot flows are available at takeoff conditions. CFD streamline rakes are shown for the full wing section in Figure 13a and in the near wake region with the slot flow discharging from the wing trailing edge in Figure 13b. With the completed CFD modeling, additional slot flow will discharge from the wing leading edge as well. More detailed grid development is required to capture both slot flows and the flow into and out of the turbofan engines. 


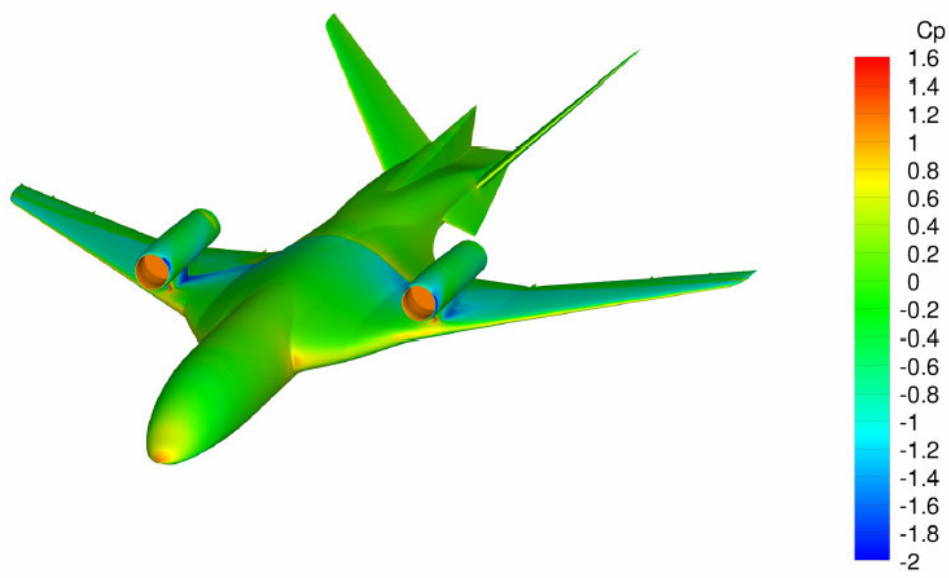

Fig. 12. Pressure Coefficient Contours for Configuration No. 1 Aircraft at Cruise

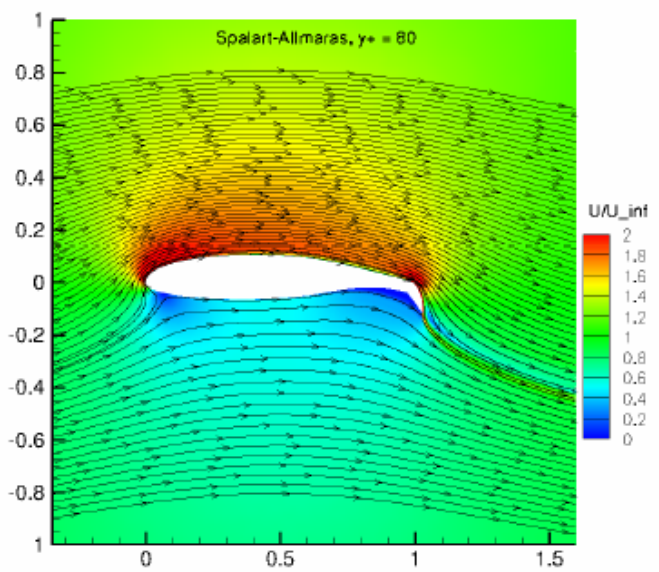

Fig. 13a. CFD Streamline Rakes for the Complete Airfoil Section at Takeoff Configuration

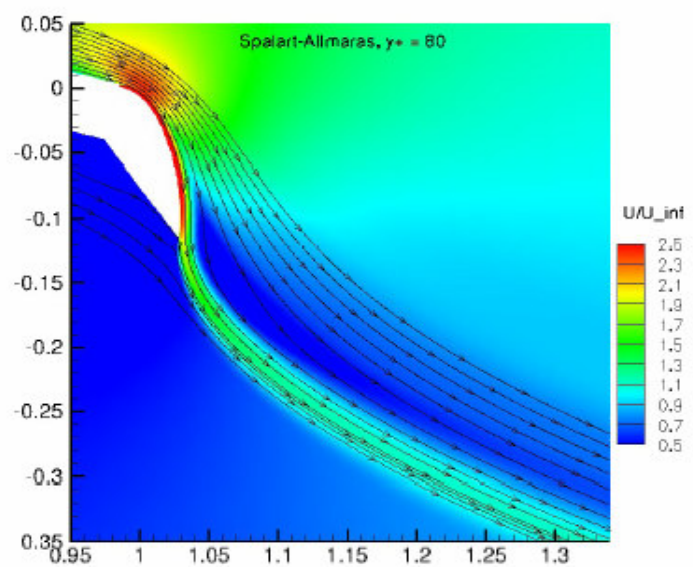

Fig. 13b. CFD Streamline Rakes in Near-Wake Region at Takeoff Configuration

In the aerodynamics meta-model now being developed, an additional parameter, the slot flow discharge total temperature, is being added as an independent parameter increasing the total number of independent 
parameters in the meta-model to five. As an added complication, the interaction between the aerodynamics and propulsion meta-models has become more involved as a result of the more detailed engine and slot flow modeling. This is described in the following section.

\section{Engine Meta-Model}

\section{A. Propulsion Meta-Model Development}

The meta-model for turbofan engines was developed using the Cal Poly Turbine Engine program (CPTE). This program is written in EXCELwith Visual-Basic MACROS for all calculations. The EXCEL sheets are used for input-output. Performance, flow path definition and component weights are computed for several turbine engine concepts. The program first designs the engine based on the input cycle parameters, and for a given engine size (either required thrust or airflow) at the sizing flight condition (usually sea-level-static, standard day), the critical engine flow path areas are determined. For this study, the engines are separate flow turbofan engines for the two engine cycles defined in Section III, and thus the defined flow path areas are the fan nozzle discharge area, core nozzle discharge area and first stator nozzle areas for the high and low pressure turbines. With these flow path area defined, the off-design program computes performance at any given flight condition. The objective for the Propulsion Meta-Model is to provide thrust, fuel flow, slot airflow and slot total temperature at each time step in the takeoff routine. The slot airflow and slot total temperature are parameters used in the aerodynamics meta-model, whereas thrust and fuel flow are used directly in the takeoff routine.

To develop a propulsion meta-model, the basic "corrected" parameters commonly used in turbine engine performance for thrust, airflow, fuel flow and temperature are used. These parameters are defined in the Nomenclature section of this paper. The independent parameter for the data is the corrected combustor exit temperature, $\mathrm{T} 4 \mathrm{C}$. This temperature is distinguished from the temperature into the first turbine rotor stage due to the mixing into the flow path of turbine first stage stators cooling air. A turbine cooling model accounts for cooling air bleed from the high pressure compressor for both the high pressure turbine and the low pressure turbine. The design point value for T4 is an input to the program, and this temperature is maintained fixed at this value throughout the Mach number range shown. The design point value for T4 is $3360{ }^{\circ} \mathrm{R}$ as given in Section III. Then T4C will vary with changes in Mach number, takeoff altitude and ambient temperature (if different from standard day at the specified altitude)

In its final form, the propulsion meta-model will be a simple routine to first size the engines with input values for aircraft gross weight, the ratio of total thrust to gross weight at takeoff (sea-level, standard day), $\mathrm{TqW}$, and wing slot geometry. For this study, air to the wing slots is taken from the fan ducts of the two engines, and input data are given for wing span, wing aspect ratio, ratio of slot span to wing span and the ratio of slot height to mean wing chord. From these geometric parameters, and slot discharge nozzle area is defined.

Figures $14-20$ represent the Propulsion Meta-Model developed for the AGTF engine cycle. The first curve of the model in Figure 14 gives the ratio of corrected airflow to design point airflow. With the inputs of aircraft gross weight and $\mathrm{TqW}$, total takeoff thrust is determined. This leads to the engine design point airflow. Note that the use of the corrected airflow collapses all airflow data at different Mach numbers onto a single curve. 


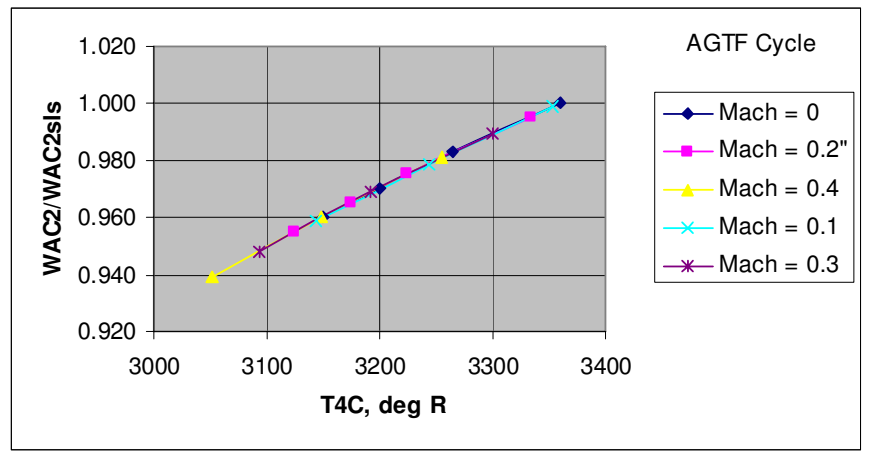

Fig. 14 Meta-Model Corrected Airflow Ratio

Figures 15-17 give the corrected specific gross thrust for the fan discharge nozzle, the slot nozzle and the core nozzle. Again, the slot flow is from the fan discharge, but an added pressure drop in the ducts to the slot reduces the specific thrust of this flow, and thus it is treated separately. Each of these specific gross thrust parameters represent gross thrust divided by the airflow at the engine inlet.

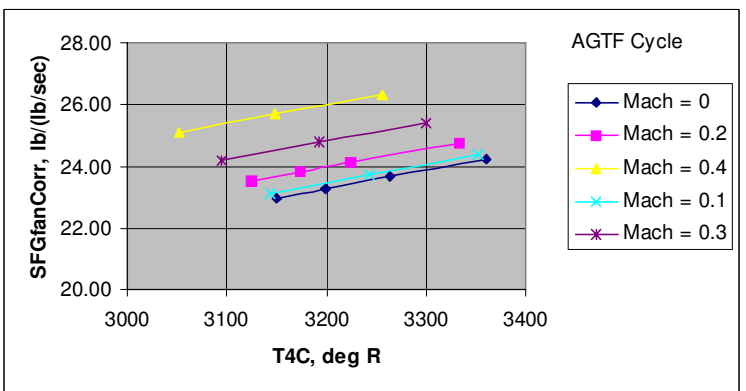

Fig. 15. Fan Nozzle Corrected Specific Thrust

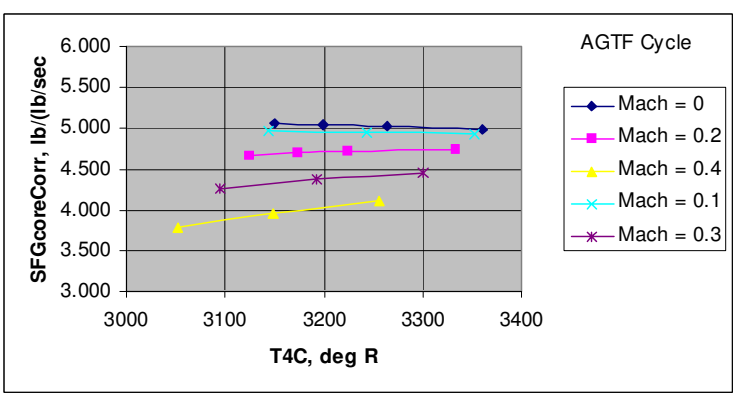

Fig. 17. Core Nozzle Corrected Specific Thrust

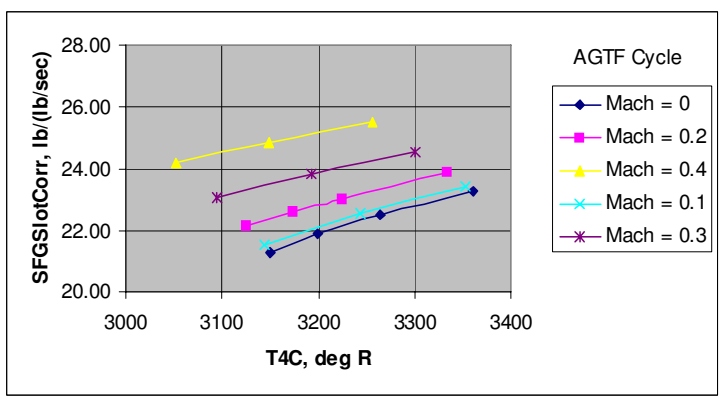

Fig. 16. Slot Nozzle Corrected Specific Thrust

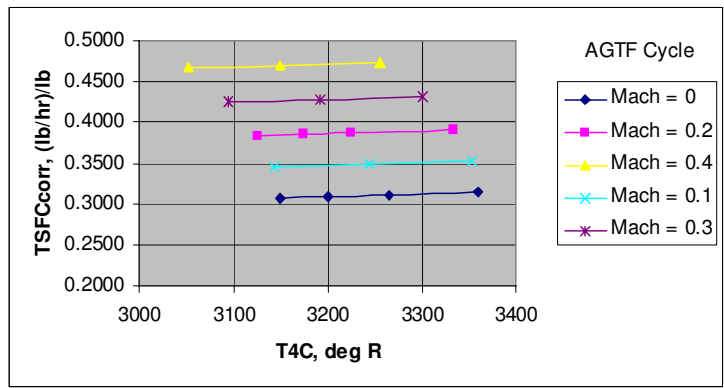

Fig. 18. Corrected Specific Fuel Consumption

Figure 18 is the corrected specific fuel consumption. This parameter is engine fuel flow divided by NET thrust to be consistent with the usual definition of specific fuel consumption. As a result, an artificial gross thrust is computed assuming all fan flow through the fan nozzle and from this value the engine ram drag is subtracted to give a value for net thrust. Fuel flow follows directly from the product of specific fuel consumption and net thrust.

The last two curves for the propulsion meta-model are given in Figures 19 and 20. They are corrected slot total temperature and engine bypass ratio, respectively. 


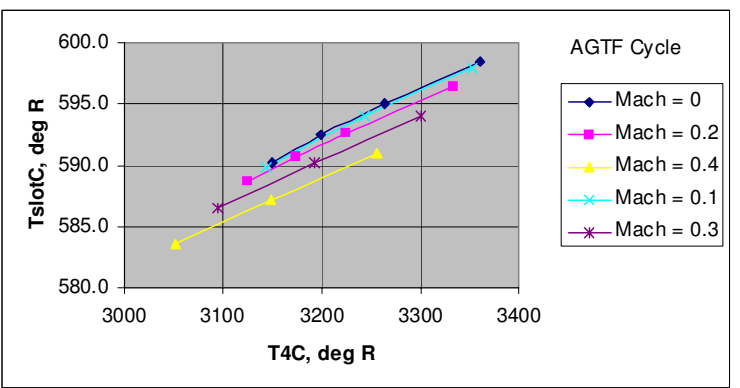

Fig. 19. Slot Corrected Total Temperature, $\operatorname{deg} \mathbf{R}$

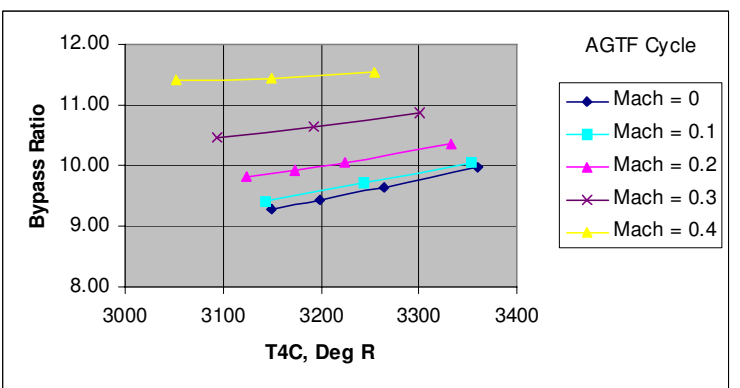

Fig. 20. Engine Bypass Ratio

These last two figures are needed for the slot total temperature and slot mass flow required by the aerodynamics meta-model. With the slot nozzle area defined by the geometric inputs defined above, the fraction of flow from the fan duct to the slot ducts is determined, and the engine bypass ratio at each takeoff time step is required.

\section{B. Representation of the Propulsion Meta-Model Using Radial Basis Functions}

In the simple propulsion program to be written that will interface with the aerodynamics meta-model and the takeoff routine, the data given in Figures 14-20 must be modeled as a propulsion meta-model and included in the propulsion program. There are any number of ways to do this including tables combined with the use of a simple table look-up procedure. However, a more sophisticated mathematical technique is being used. As described previously a meta-model is basically a model of a model. The meta-model uses sparse points from the original model whether they be CFD predictions of aerodynamic data, takeoff performance at different conditions, or an engine performance model, and predicts the rest of the points in the data space. The meta-model is used on more complex models to create a less complex model that is faster to run than the original model. There is some error associated with using meta-models, but the errors are generally small and the time saved can be quite large. There are many types of meta-models which include polynomial regression, kriging method (Gaussian Processes), Multivariate adaptive regression splines (MARS), and radial basis functions (RBF) to name a few of the popular techniques. The metamodel technique used to model the engine performance program is RBF.

RBF is used in this project because of its robustness and ease of creating a model. The engine performance parameters that are modeled are fairly linear, so RBF is be able to capture the trends and be able to create an accurate model. RBF was also a good choice because it is less time consuming than other metamodeling techniques, and it is much faster than the CPTE program used to develop the basic data.

RBF works by creating a matrix of the Euclidean distance of the training points, called the radius matrix. A function is then created using basis functions with odd powers of $r$. The basis function used for this metamodel is shown in the equation below.

$$
\mathrm{F}=1+\mathrm{r}^{3}
$$

Every point has an associated coefficient value which is found using the function above and the training points. These coefficients are used to find the value of the test points. The Euclidean distance is found from the test points and training points. The same function is used to obtain the function for the test points. The value of the test points develops from the product of the test function matrix and the coefficient matrix. The thing to look out for in this meta-model technique is to make sure the training points are scaled to values between zero and one.

The RBF meta-model is applied to the data given in Figures 14-20. The independent parameters used by the meta-model are the Mach number and the corrected combustor exit temperature, T4C. The T4C parameter is determined from inputs to the propulsion program of the value for $\mathrm{T} 4$, the altitude, and the change in standard day temperature from standard day. The RBF meta-models then give values for the parameters given in Figures 14-20, and from these net thrust, fuel flow, slot mass flow and slot total temperature are outputs from the program. 
The meta-model will work well with the takeoff program described below. The methods being used to produce a meta-model is in the process of being automated. To do so, the CPTE engine performance code is run to get a small number of data points representing the data shown in Figures 14-20. With these few data points, the RBF meta-model can be used for the rest of the data points needed by the takeoff program.

\section{Application of the Propulsion Meta-Model}

To demonstrate the application of the propulsion meta-model, an aircraft with a takeoff gross weight of $95,000 \mathrm{lb}$ and a TqW of 0.45 is defined. Thus the total design point aircraft thrust is $42,750 \mathrm{lb}$, and since this is a twin engine aircraft the design point engine thrust at sea level static is $21,375 \mathrm{lb}$. This design point assumes an inlet pressure recovery of 1.0, but with the use of the corrected parameters, a pressure recovery schedule can be defined. For this example the schedule shown in Figure 21 is used.

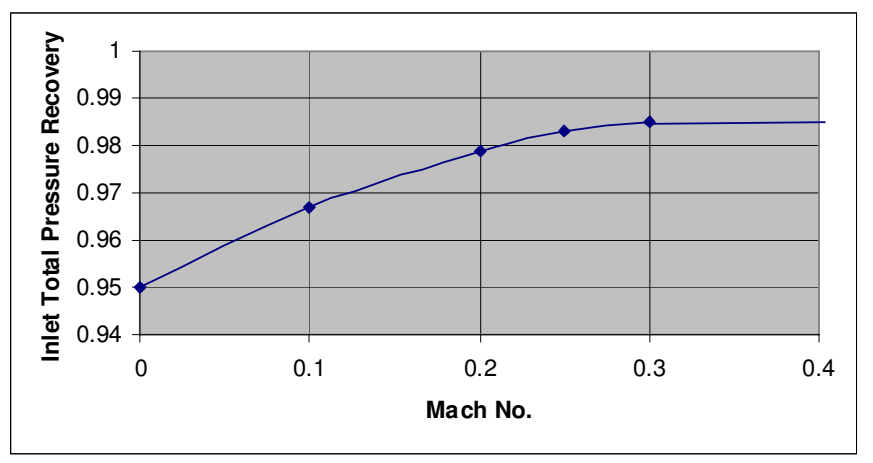

Fig. 21. Assumed Inlet Total Pressure Recovery

The takeoff is at sea level on a standard day, and the total aircraft thrust from brake release to a Mach number of 0.4 is shown in Figure 22. Liftoff is likely to occur at a Mach number between 0.1 and 0.15 , so the assumption of sea level throughout introduces a slight error at higher Mach numbers. Both the AGTF and the ACTF engines are shown on the figure, and, as one would expect, the thrust for the higher bypass engine (AGTF) decays faster with increasing speed. Note that the thrust shown at Mach $=0$ is slightly less than the design point value of $42,750 \mathrm{lb}$. This reflects the inlet pressure recovery of 0.95 at this point.

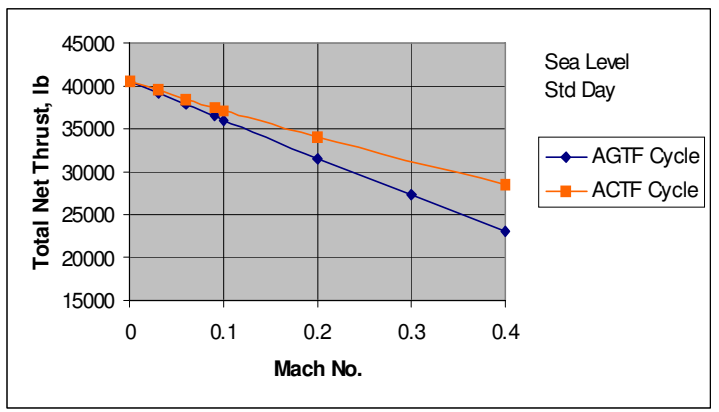

Fig. 22. Total Thrust with Mach No.

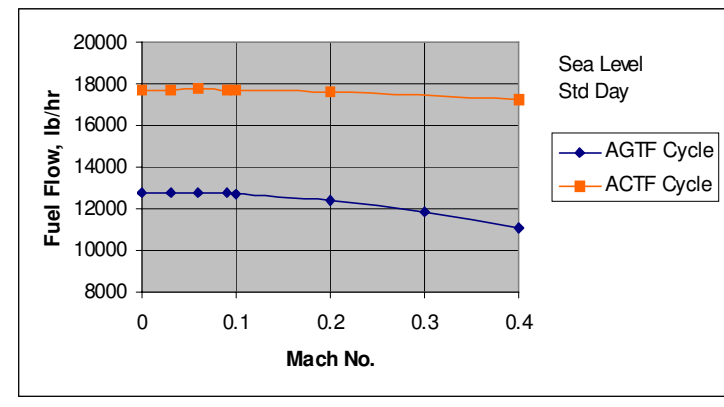

Fig. 23. Total Fuel Flow with Mach No.

The, total fuel flow is shown in Figure 23 with the AGTF engine cycle engine having a significantly lower fuel burn rate. Again, this is to be expected for this higher bypass ratio engine. These two parameters are computed from the meta-model functions and they will pass directly to the takeoff program at each time step of the takeoff run. 
The slot geometry for the aircraft is set by the following geometric characteristics of the aircraft:

Wing Span $=132.9 \mathrm{ft}$

Wing Aspect Ratio $=8.58$

Ratio of Slot Span to Wing Span $=0.709$

Ratio of Slot Height to Mean Wing Chord $=0.0042$

From these parameters, the slot nozzle area is determined, and a simple iteration in the propulsion program determines the ratio of Slot Flow to Fan Discharge Flow, BLfract. This is done at the design point, and this ratio is maintained for all off-design cases. For the AGTF engine, BLfract $=0.387$ and for the ACTF engine $B L$ fract $=0.573$. These values compare with the results shown in Figure 8 for given value of Ratio of Slot Height to Mean Wing Chord ratio of 0.0042. As part of this iteration, a fraction of the flow to the slots is ducted to the leading edge slot. For this example, the ratio of leading edge slot flow to trailing edge slot flow, BLfractLE, is 0.6. As stated in Section III, it is assumed there is no axial thrust from the leading edge slot. The result of this iteration is the total slot airflow, which is shown in Figure 24 over the range of Mach number. This value is to be used by the aero meta-model at each time step in the takeoff program.

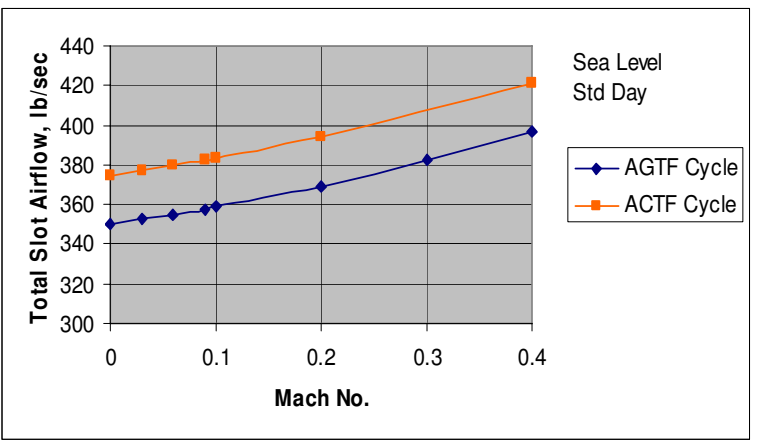

Fig. 24. Total Slot Airflow with Mach No.

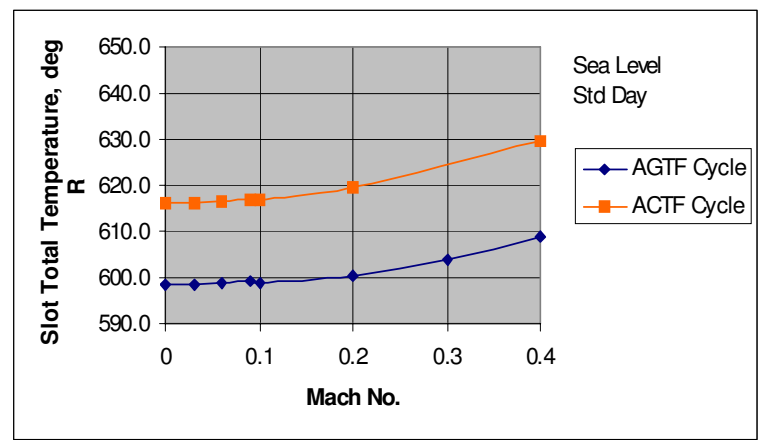

Fig. 25. Slot Total Temperature with Mach No

The slot total temperature is shown in Figure 25. Along with the slot airflow, this parameter is used in the Aero Meta-Model to compute slot velocity at each time step. To reiterate, the data in Figures 22-25 are generated automatically in the propulsion meta-model at each time step in the takeoff calculations and then passed to the Aero meta-model and the takeoff program.

The momentum coefficient, $C \mu$, at each time step is also computed. This parameter is not used directly in either the aero meta-model or the takeoff program, but it is interesting to compare $\mathrm{C} \mu$ for the two engine cycles. This is done in Figure 26.

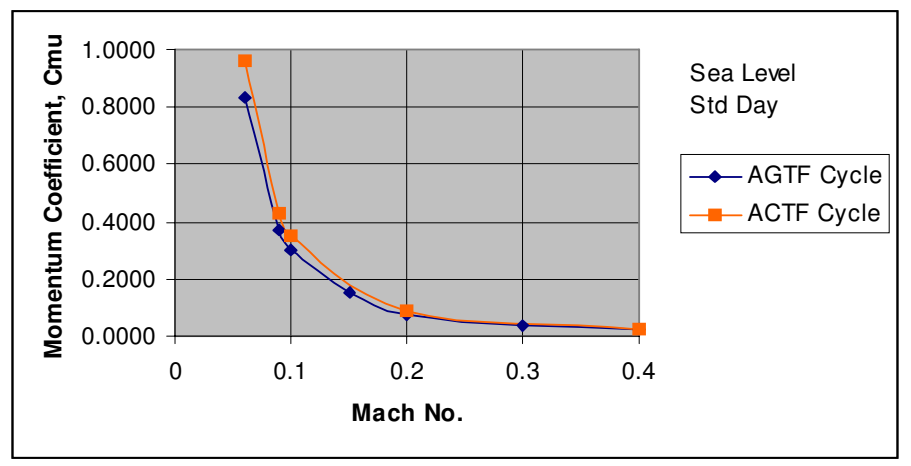

Fig. 26. Momentum Coefficient over the Mach No. range for the two Engine Cycles

The figure shows the very non-linear nature of $\mathrm{C} \mu$ with its value going to infinity as Mach number (dynamic pressure) goes to zero. 


\section{TAKEOFF PROGRAM DESCRIPTION}

The dynamics of the ground roll and trajectory calculations developed for this project started with an extensive evaluation of a much older code from the NASA written in FORTRAN, and a re-write of this program written in MATLAB was achieved. Validation started off with the simplest cases to verify the integration techniques. This involved having constant thrust, lift and drag coefficient values and integrating by hand up to the rotation speed and then comparing the values. Having verified that the ODE45 integration function of MATLAB was being used correctly, the next step was to use the same aerodynamics and thrust models as the FORTRAN version and compare trajectory paths. The results look promising but not precisely exact. For 20,000 ft from brake release, the altitude for the Fortran output is $1662 \mathrm{ft}$ while the MATLAB output is $1598 \mathrm{ft}$, a difference of $64 \mathrm{ft}$. After a time lapse of 98 seconds have pasted into the trajectory, this is an error of $3.85 \%$ from the FORTRAN output. The results continue to diverge as the trajectory progresses. The FORTRAN code is not considered to be a standard that must be replicated. The MATLAB integration module, ODE45, is much more sophisticated than the simple Runge-Kutta scheme used in the FORTRAN code, and thus the results shown for the new MATLAB code are considered to be the more accurate of the two programs.

The Take-Off Analysis program is used to simulate a flight during each take-off stage, including ground roll, first and second segment climb. If necessary the program can be extended to climb to cruise altitude with selecting one of several options including minimum time to climb or minimum fuel to climb. For the takeoff trajectory, schedules are input to the program for gear retraction, flap deployment and heading changes. In addition, there is provision for a thrust vectoring schedule. The program requires the interface of a propulsion module to predict thrust and fuel flow and an aerodynamic module to predict lift and drag coefficients. Interfacing with the aerodynamics and propulsion meta-models described above will allow the calculation of powered-lift takeoff distance. At present this is a feature not available in any code known to this project team.

In addition to the trajectory calculations, the Take-Off Analysis program also computes a balanced field length for constant flap deflection angles, and blowing values in the case of powered-lift. It will calculate the braking and take-off distance for any number of velocities throughout the take-off time period. Then, using a MATLAB function, a quadratic polynomial curve is fit to the data. The Take-Off program then subtracts the two polynomial curve equations and finds the roots. One of those roots corresponds to the same distance for take-off and braking and this velocity root is the decision speed, V1. This decision speed is the same velocity where the take-off and braking curves intersect, i.e., the distance to climb to 35 feet with one engine inoperative (OEI) and the distance to brake the aircraft to a complete stop are the same. It should be noted that with the loss of an engine there is additional drag due to the wind-milling engine and the deployment of the rudder to control yaw. These drag increments are being computed and added to total drag in this program. As an example of this capability, a model without blowing has been used to demonstrate the output for the balance field length calculations. Figure 27 shows the distance to stop or reach the $35 \mathrm{ft}$ clearance as a function of the decision speed for a constant flap deflection.

Once the meta-models are in place, it remains to develop the most efficient procedure to apply this takeoff model to compute powered-lift takeoff distance. A traditional takeoff procedure defines the stall speed and then sets a value for V1 at nominally $1.05 *$ stall speed. Then rotation speed, VR, is set at a speed higher than V1 but before liftoff when lift = weight. With powered-lift, the plan is to define V1 based on the balanced field length calculation outlined above. Then, VR can be set at higher velocities so long as lift < aircraft weight. A sub-optimization, will be required to a value for VR that will minimize takeoff distance considering both the ground roll to liftoff and the climb to the screen height. This sub-optimization will be determined primarily by the flap setting selected for the aircraft.

American Institute of Aeronautics and Astronautics 


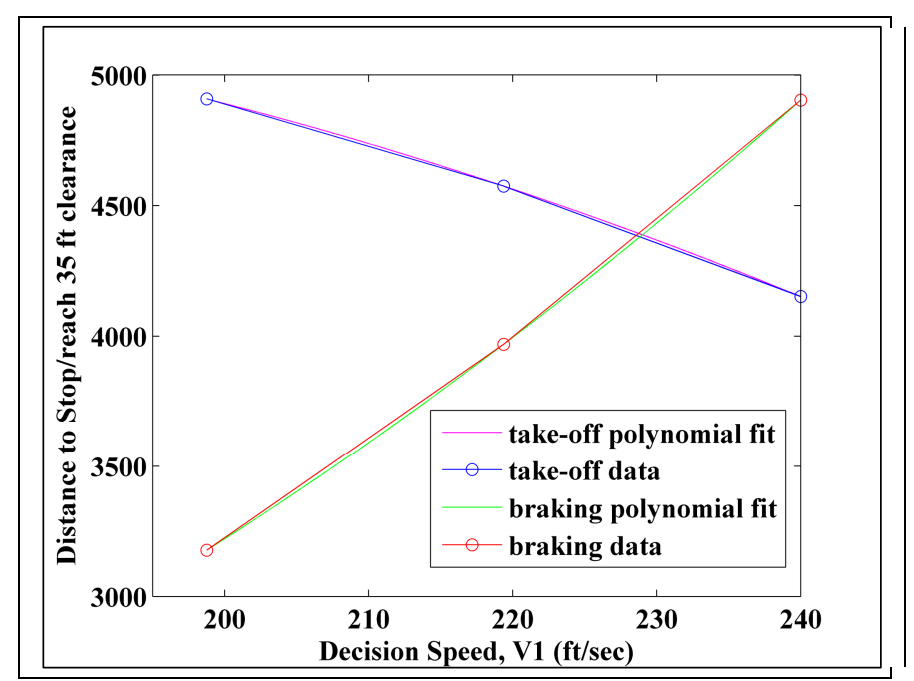

Fig. 27. Balanced Field Length Polynomial Curve Fits

\section{CONCLUDING REMARKS}

The original objective of this paper was to complete aero and propulsion meta-models for the Cal Poly Configuration No. 1 aircraft and determine an engine size to meet a STOL takeoff distance. This objective has not been met because the necessary meta-models are not complete. The development of the aero metamodel is truly a large task requiring the full navier-stokes CFD modeling of a complete aircraft configuration with circulation-control slot blowing through the wing trailing and leading edges. However, this paper is offered as a progress report toward the objective, and as such it serves as a valuable addition to first define the aircraft configurations that have been studied at Cal Poly through the NASA NRA contract, to define the configuration that has been selected to be carried into Phase II of the contract and to define the propulsion system for this selected aircraft configuration.

The basic procedure to apply aerodynamic and propulsion meta-models to compute powered-lift takeoff has been established in reference 1. In that paper, the propulsion model that was used is considered too simplistic, and the major contribution of the study presented herein is the definition of a robust method of propulsion system meta-modeling that starts with the basic definition of the design point engine cycle and produces a model that gives accurate engine thrust, fuel flow, slot flow and slot total temperature over the complete takeoff run and initial climb. In addition, a procedure has been established for sizing the wing slots, which are constrained by geometric ratios that have been found to be required for good circulationcontrol-wing $(\mathrm{CCW})$ aerodynamic performance.

Two engine cycles were studied carefully, one a representation of the high bypass ratio $(\mathrm{BPR}=10)$ geared turbofan engine now being developed by Pratt and Whitney and the other a lower bypass ratio $(B P R=5)$ engine with a relatively high fan pressure ratio. At this time, no conclusion whether either engine cycle is superior can be made. That will require not only takeoff calculations but also a full simulation of the aircraft mission to obtain a measure of mission fuel-burn.

Finally, a detailed takeoff program has been completed using MATLAB. It has proven to be quite versatile, not only for takeoff calculations, but initial climb including curved departures. A longer range project objective is to combine this takeoff program with a engine source noise program and a noise contour program to study the impact of aircraft design and operations on the noise impact in the airport environs. This study of powered-lift takeoff will continue along with the overall Cal Poly Phase II NRA project, and it is the intention to meet the original objective of the project to compute powered-lift takeoff performance. 
This work was funded as part of a NASA Research Announcement award under Contract \#NNL07AA55C with Craig Hange and Joe Posey as the technical monitors.

\section{References}

1. Ball, Tyler, Turner, Scott, Marshall, David, "Short Field Performance Using Circulation Control," AIAA 2008-174.

2. The Integrated Modeling and Verification of Hybrid Wing-Body Low Noise ESTOL Aircraft, NASA Fundamental Aeronautics - Subsonic Fixed Wing Program Contract \# NNL07AA55C 